\title{
Effects of drinking hydrogen-rich water on the quality of life of patients treated with radiotherapy for liver tumors
}

Ki-Mun Kang ${ }^{1}$, Young-Nam Kang ${ }^{1}$, Ihil-Bong Choi ${ }^{1,2}$, Yeunhwa Gu ${ }^{2,3}$, Tomohiro Kawamura ${ }^{4}$, Yoshiya Toyoda ${ }^{4}$ and Atsunori Nakao ${ }^{4,5^{*}}$

\begin{abstract}
Background: Cancer patients receiving radiotherapy often experience fatigue and impaired quality of life (QOL). Many side effects of radiotherapy are believed to be associated with increased oxidative stress and inflammation due to the generation of reactive oxygen species during radiotherapy. Hydrogen can be administered as a therapeutic medical gas, has antioxidant properties, and reduces inflammation in tissues. This study examined whether hydrogen treatment, in the form of hydrogen-supplemented water, improved QOL in patients receiving radiotherapy.
\end{abstract}

Methods: A randomized, placebo-controlled study was performed to evaluate the effects of drinking hydrogenrich water on 49 patients receiving radiotherapy for malignant liver tumors. Hydrogen-rich water was produced by placing a metallic magnesium stick into drinking water (final hydrogen concentration; 0.55 0.65 mM). The Korean version of the European Organization for Research and Treatment of Cancer's QLQ-C30 instrument was used to evaluate global health status and QOL. The concentration of derivatives of reactive oxidative metabolites and biological antioxidant power in the peripheral blood were assessed.

Results: The consumption of hydrogen-rich water for 6 weeks reduced reactive oxygen metabolites in the blood and maintained blood oxidation potential. QOL scores during radiotherapy were significantly improved in patients treated with hydrogen-rich water compared to patients receiving placebo water. There was no difference in tumor response to radiotherapy between the two groups.

Conclusions: Daily consumption of hydrogen-rich water is a potentially novel, therapeutic strategy for improving $\mathrm{QOL}$ after radiation exposure. Consumption of hydrogen-rich water reduces the biological reaction to radiationinduced oxidative stress without compromising anti-tumor effects.

\section{Background}

Radiotherapy is one of the major treatment options for malignant neoplasms. Nearly half of all newly diagnosed cancer patients will receive radiotherapy at some point during treatment and up to $25 \%$ may receive radiotherapy a second time [1]. While radiotherapy destroys malignant cells, it adversely affects the surrounding normal cells [2]. Acute radiation-associated side effects include fatigue, nausea, diarrhea, dry mouth, loss of

\footnotetext{
* Correspondence: anakao@imap.pitt.edu

${ }^{4}$ Department of Cardiothoracic Surgery, University of Pittsburgh, Pittsburgh, Pennsylvania, USA

Full list of author information is available at the end of the article
}

appetite, hair loss, sore skin, and depression. Radiation increases the long-term risk of cancer, central nervous system disorders, cardiovascular disease, and cataracts. The likelihood of radiation-induced complications is related to the volume of the irradiated organ, the radiation dose delivered, the fractionation of the delivered dose, the delivery of radiation modifiers, and individual radiosensitivity [3]. Most radiation-induced symptoms are believed to be associated with increased oxidative stress and inflammation, due to the generation of reactive oxygen species (ROS) during radiotherapy, and may significantly affect the patient's quality of life (QOL) [2].
Ciomed Central

(c) 2011 Kang et al; licensee BioMed Central Ltd. This is an Open Access article distributed under the terms of the Creative Commons Attribution License (http://creativecommons.org/licenses/by/2.0), which permits unrestricted use, distribution, and reproduction in any medium, provided the original work is properly cited. 
Hydrogen, a therapeutic medical gas, has antioxidant properties and reduces inflammatory events in tissues [4-6]. Drinking liquids supplemented with hydrogen represents a novel method of hydrogen gas delivery that is easily translatable into clinical practice, with beneficial effects for several medical conditions, including atherosclerosis, type 2 diabetes, metabolic syndrome, and cognitive impairment during aging and in Parkinson's disease [7-11]. Currently, there is no definitive therapy to improve the QOL of patients receiving radiotherapy. Drinking solubilized hydrogen on a daily basis may be beneficial and would be quite easy to administer without complicating or changing a patient's lifestyle. We hypothesized that oral intake of hydrogen-rich water, generated via a magnesium stick, would reduce adverse events in patients receiving radiotherapy.

\section{Methods}

\section{Subjects and design}

The study was a two-arm, randomized, controlled clinical trial. Patients were randomly assigned to receive either hydrogen-rich water or placebo water on the first day of radiation treatment, and received follow-up questionnaires on compliance and potential adverse effects. Eligible patients were informed of the study during scheduling of pre-radiation testing. Patient characteristics, including tumor origin and the specifics of radiotherapy, are listed in Table 1. Forty-nine subjects (33 men and 16 women) were enrolled between April and October 2006. The age of the patients ranged from 21 to 82 years (mean age 58.6 years). All patients were diagnosed either histologically or pathologically with hepatocellular carcinoma (HCC) or metastatic hepatic tumors. All participants received 5040-6500 cGy of radiotherapy for 7-8 weeks using a $6 \mathrm{MV}$ system (Cyber Knife, Fanuc, Yamanashi, Japan). The planned target volume of the initial field was assessed by a localization/ simulation procedure or by computed tomography (CT)-assisted planning and encompassed the primary tumors and a $2 \mathrm{~cm}$ margin. Blocks were used to shield normal tissue.

Hydrogen-rich water was produced by placing a metallic magnesium stick (Doctor SUISOSUI ${ }^{\circledR}$, Friendear, Tokyo, Japan) into drinking water $\left(\mathrm{Mg}+2 \mathrm{H}_{2} \mathrm{O} \rightarrow\right.$ $\mathrm{Mg}(\mathrm{OH})_{2}+\mathrm{H}_{2}$; final hydrogen concentration: $0.55 \sim 0.65 \mathrm{mM})$. The magnesium stick contained $99.9 \%$ pure metallic magnesium and natural stones in a polypropylene and ceramic container. The subjects were randomly assigned to groups to either drink hydrogenrich water for 6 weeks $(n=25)$ or drink water containing a placebo (a casing-only stick placed in drinking water) $(n=24)$. Subjects were provided with four 500 $\mathrm{mL}$ bottles of drinking water per day and instructed to place two magnesium sticks in each bottle of water at the end of each day in preparation for consumption the following day. Participants were asked to drink 200-300 $\mathrm{mL}$ from one bottle each morning, and 100-200 mL every a few hours from the remaining three bottles. Subjects were instructed to reuse the magnesium sticks by transferring the sticks to a new bottle of water after use. The subjects were expected to consume 100-300 mL of hydrogen-rich water more than 10 times per day for a total minimum consumption of $1500 \mathrm{~mL}(1.5 \mathrm{~L})$ and a maximum consumption of $2000 \mathrm{~mL}(2.0 \mathrm{~L})$. Oral intake of hydrogen water or placebo water started on the first day of radiotherapy and continued for 6 weeks. All the patients survived through the 6 week follow-up period when the QOL questionnaire was administered. This study was conducted in accordance with Good Clinical Practice guidelines and the ethical principles of the Declaration of Helsinki (2000). The study protocol and materials were approved by the Institutional Review Board of Catholic University Medical College, and all subjects provided written informed consent prior to participation.

\section{QOL Assessment}

The Korean version of the European Organization for Research and Treatment of Cancer's QLQ-C30 instrument with modifications was used to evaluate global health status and create QOL scales [12]. The descriptive, mailed survey developed by our institute was used in this study. The questionnaire contains five functional scales (physical, cognitive, emotional, social, and rolefunctioning), three symptom scales (pain, fatigue, and nausea/vomiting), and six single items to assess additional symptoms (dyspnea, insomnia, loss of appetite, constipation, diarrhea). For all items, a response scale ranging from 0-5 was used. A higher score reflected a higher level of symptoms and decreased QOL. Assessments were performed before radiotherapy and every week for 6 weeks after the initiation of radiotherapy.

\section{Biomarker analysis}

The concentrations of derivatives of reactive oxidative metabolites (dROMs) and biological antioxidant power (BAP) in the peripheral blood were assessed using a free Radical Analytical System (FRAS4; H\&D, Parma, Italy) on the first day of radiation therapy (week 0) and after 6 weeks of radiotherapy. Blood samples were obtained from all patients after overnight fasting. FRAS4 dROMs kits were used to measure total hydroperoxide levels, which are representative of the total dROMs produced as a result of peroxidation chain reactions of proteins, lipids, and amino acids. Results were expressed in U. CARR; 1 U.CARR is equivalent to $0.08 \mathrm{mg} / \mathrm{dl}$ of hydrogen peroxide and the value is directly proportional to the concentration, according to Lambert-Beer's law. 


\begin{tabular}{|c|c|c|c|c|c|c|c|c|c|c|c|c|c|c|c|c|c|c|c|c|}
\hline & water & Age & gender & times & diagnosis & $\begin{array}{l}\text { isodose } \\
\text { curve } \\
(\%)\end{array}$ & $\begin{array}{l}\text { total } \\
\text { cGy }\end{array}$ & $\begin{array}{l}\text { volume } \\
\text { (cc) }\end{array}$ & $\begin{array}{l}\text { collimater } \\
\text { (cc) }\end{array}$ & response & water & age & gender & times & diagnosis & $\begin{array}{l}\text { isodose } \\
\text { curve } \\
(\%)\end{array}$ & $\begin{array}{l}\text { total } \\
\text { cGy }\end{array}$ & $\begin{array}{l}\text { volume } \\
\text { (cc) }\end{array}$ & $\begin{array}{l}\text { collimater } \\
\text { (cc) }\end{array}$ & response \\
\hline 1 & placebo & 76 & $M$ & $\begin{array}{l}3 \\
3\end{array}$ & $\mathrm{HCC}$ & $\begin{array}{l}80 \\
75\end{array}$ & $\begin{array}{l}3,900 \\
3,900\end{array}$ & $\begin{array}{l}2.521 \\
2.746\end{array}$ & $\begin{array}{l}7.5 \\
7.5\end{array}$ & NR & $\mathrm{HW}$ & 52 & $M$ & 3 & $\begin{array}{l}\text { liver meta } \\
\text { of colon } \\
\text { ca }\end{array}$ & 74 & 3,600 & 12.283 & 15 & NR \\
\hline 2 & placebo & 82 & $M$ & 1 & $\mathrm{HCC}$ & 70 & 1,200 & 11.769 & 20 & $C R$ & $\mathrm{HW}$ & 56 & $M$ & 3 & $\begin{array}{l}\text { liver meta } \\
\text { of colon } \\
\text { ca }\end{array}$ & 85 & 3,600 & 2.552 & 12.5 & $P R$ \\
\hline 3 & placebo & 57 & $\mathrm{~F}$ & 3 & $\begin{array}{l}\text { bile duct } \\
\text { ca }\end{array}$ & 80 & 3,000 & 40.334 & 30 & $P R$ & HW & 77 & $F$ & 3 & $\begin{array}{l}\text { liver meta } \\
\text { of colon } \\
\text { ca }\end{array}$ & 75 & 3,000 & 107.136 & 20 & $C R$ \\
\hline 4 & placebo & 47 & $\mathrm{~F}$ & 9 & $\begin{array}{l}\text { liver meta. } \\
\text { of sarcoma }\end{array}$ & $\begin{array}{l}80 \\
82 \\
84\end{array}$ & $\begin{array}{l}3,600 \\
3,600 \\
3,900\end{array}$ & $\begin{array}{l}10.628 \\
6.542 \\
2.673\end{array}$ & $\begin{array}{l}25 \\
20 \\
15\end{array}$ & NR & HW & 57 & $M$ & 3 & $\mathrm{HCC}$ & 70 & 3,600 & 47.679 & 15 & NR \\
\hline 5 & placebo & 50 & $\mathrm{~F}$ & 3 & $\begin{array}{l}\text { liver meta } \\
\text { of colon } \\
\text { ca }\end{array}$ & 80 & 3,900 & 16.237 & 20 & NR & HW & 66 & $M$ & 3 & $\mathrm{HCC}$ & 80 & 3,600 & 16.216 & 25 & $P R$ \\
\hline 6 & placebo & 21 & $\mathrm{~F}$ & 3 & $\begin{array}{c}\text { liver meta. } \\
\text { of ovarian } \\
\text { ca }\end{array}$ & 85 & 3,600 & 29.398 & 30 & $C R$ & HW & 57 & $M$ & 3 & $\mathrm{HCC}$ & 80 & 3,600 & 35.303 & 30 & NR \\
\hline 7 & placebo & 65 & $M$ & 3 & $\begin{array}{l}\text { liver meta. } \\
\text { of rectal } \\
\text { ca }\end{array}$ & 70 & 3,000 & 182.871 & 40 & $P R$ & $\mathrm{HW}$ & 47 & $M$ & 3 & $\mathrm{HCC}$ & 77 & 3,000 & 17.65 & 20 & $C R$ \\
\hline 8 & placebo & 73 & $M$ & 3 & $\begin{array}{l}\text { liver meta. } \\
\text { of rectal } \\
\text { ca }\end{array}$ & 75 & 3,600 & 37.937 & 20 & $P R$ & HW & 49 & $M$ & 3 & $\mathrm{HCC}$ & 80 & 3,300 & 53.578 & 12.5 & $P R$ \\
\hline 9 & placebo & 58 & $M$ & 3 & $\begin{array}{l}\text { liver meta. } \\
\text { of } \\
\text { pancreatic } \\
\text { ca }\end{array}$ & 75 & 3,000 & 65.637 & 35 & $C R$ & $\mathrm{HW}$ & 71 & $F$ & 3 & $\mathrm{HCC}$ & 85 & 3,000 & 3.861 & 10 & NR \\
\hline 10 & placebo & 64 & M & 3 & $\mathrm{HCC}$ & 70 & 3,000 & 140.136 & 20 & $P R$ & HW & 45 & $M$ & 3 & $\mathrm{HCC}$ & 80 & 3,600 & 28.286 & 15 & NR \\
\hline 11 & placebo & 65 & $F$ & 3 & $\mathrm{HCC}$ & 70 & 3,600 & 48.645 & 25 & PR & HW & 45 & F & 3 & $\begin{array}{l}\text { liver meta. } \\
\text { of gastric } \\
\text { ca }\end{array}$ & 85 & 3,000 & 38.938 & 15 & PR \\
\hline 12 & placebo & 80 & $M$ & 3 & $\mathrm{HCC}$ & 80 & 3,000 & 209.954 & 25 & NR & HW & 56 & $F$ & 3 & $\begin{array}{l}\text { Adrenal } \\
\text { metastasis } \\
\text { of HCC }\end{array}$ & 80 & 3,600 & 9.494 & 15 & $P R$ \\
\hline 13 & placebo & 56 & $M$ & 3 & $\mathrm{HCC}$ & 85 & 3,600 & 15.365 & 15 & $C R$ & HW & 49 & $M$ & 3 & $\begin{array}{l}\text { Adrenal } \\
\text { metastasis } \\
\text { of HCC }\end{array}$ & 75 & 3,000 & 91.223 & 20 & NR \\
\hline 14 & placebo & 61 & $\mathrm{~F}$ & 3 & $\mathrm{HCC}$ & 70 & 3,000 & 98.957 & 30 & NR & HW & 60 & $M$ & 3 & $\begin{array}{c}\mathrm{LN} \\
\text { metastasis } \\
\text { of HCC }\end{array}$ & 75 & 3,000 & 120.366 & 25 & NR \\
\hline
\end{tabular}




\section{Table 1 Patient Characteristics (Continued)}

\begin{tabular}{|c|c|c|c|c|c|c|c|c|c|c|c|c|c|c|c|c|c|c|c|c|}
\hline 15 & placebo & 46 & $M$ & 3 & $\mathrm{HCC}$ & 80 & 3,000 & 20.848 & 25 & $C R$ & $\mathrm{HW}$ & 47 & $M$ & 3 & $\begin{array}{c}\text { LN } \\
\text { metastasis } \\
\text { of HCC }\end{array}$ & 80 & 3,000 & 80.459 & 25 & NR \\
\hline 16 & placebo & 70 & $F$ & 3 & $\mathrm{HCC}$ & 85 & 3,600 & 16.908 & 20 & PR & HW & 50 & $M$ & 3 & $\mathrm{HCC}$ & 75 & 3,600 & 29.422 & 20 & $N R$ \\
\hline 17 & placebo & 44 & $M$ & 3 & $\mathrm{HCC}$ & 85 & 3,600 & 16.612 & 30 & $N R$ & HW & 49 & $F$ & 3 & $\mathrm{HCC}$ & 70 & 3,000 & 156.289 & 40 & $P R$ \\
\hline 18 & placebo & 48 & $\mathrm{M}$ & 3 & $\mathrm{HCC}$ & 85 & 3,000 & 35.093 & 20 & $\mathrm{NR}$ & $\mathrm{HW}$ & 63 & $F$ & 3 & $\mathrm{HCC}$ & 75 & 3,900 & 5.425 & 20 & NR \\
\hline 19 & placebo & 76 & $\mathrm{~F}$ & 3 & $\mathrm{HCC}$ & 85 & 3,600 & 5.75 & 15 & NR & HW & 51 & M & 3 & $\mathrm{HCC}$ & 70 & 4,000 & 28.637 & 35 & NR \\
\hline 20 & placebo & 60 & M & 3 & $\mathrm{HCC}$ & 83 & 3,600 & 6.802 & 12.5 & NR & HW & 67 & $\mathrm{~F}$ & 3 & $\mathrm{HCC}$ & 80 & 3,600 & 20.122 & 20 & PR \\
\hline 21 & placebo & 77 & $M$ & 3 & $\mathrm{HCC}$ & 75 & 3,300 & 33.282 & 25 & PR & $\mathrm{HW}$ & 56 & $M$ & 3 & $\mathrm{HCC}$ & 70 & 3,600 & 23.5 & 20 & $C R$ \\
\hline 22 & placebo & 55 & $M$ & 3 & $\mathrm{HCC}$ & 83 & 3,600 & 11.963 & 20 & $N R$ & HW & 78 & $F$ & 3 & $\mathrm{HCC}$ & 83 & 3,600 & 26.456 & 25 & NR \\
\hline 23 & placebo & 57 & $M$ & 3 & $\mathrm{HCC}$ & 70 & 3,000 & 75.782 & 40 & $N R$ & $\mathrm{HW}$ & 56 & $M$ & 3 & $\mathrm{HCC}$ & 77 & 3,600 & 31.908 & 20 & $C R$ \\
\hline \multirow[t]{2}{*}{24} & placebo & 65 & $M$ & 2 & $\mathrm{HCC}$ & 75 & 3,000 & 55.191 & 25 & NR & $\mathrm{HW}$ & 60 & $M$ & 3 & $\mathrm{HCC}$ & 70 & 3,600 & 36.479 & 30 & $P R$ \\
\hline & & & & & & & & & & & $\mathrm{HW}$ & 70 & $M$ & 3 & $\mathrm{HCC}$ & 76 & 3,600 & 63.434 & 40 & NR \\
\hline
\end{tabular}

M: male, F: female, HCC: hepatocellular carcinoma, NR: no response, PR: partial response, CR: complete response, HW: hydrogen water. 
Redox potential, including glutathione peroxidase and superoxide dismutase, were determined using the FRAS4 BAP test [13]. Described briefly, the samples to be tested were dissolved in a colored solution containing a source of ferric ions and a chromogenic substance (a sulfur-derived compound). After a 5-minute incubation period, the degree of discoloration and intensity of the change were directly proportional to the ability of the plasma to reduce ferric ions. The amount of reduced ferric ions was calculated using a photometer to assess the intensity of discoloration; BAP results were expressed as $\mu \mathrm{mol} / \mathrm{l}$ of reduced $\mathrm{Fe} / \mathrm{l}$.

Blood chemistry tests for aspartate aminotransferase, alanine aminotransferase, gamma-glutamyl transpeptidase $(\gamma-$ GTP), and total cholesterol, as well as blood hematology tests for red blood cell count, white blood cell count, and platelet count were conducted at week 0 and week 6 using standard assays in an accredited hospital laboratory.

\section{Assessment of response}

Patients underwent dynamic CT scans 1-2 months after completion of radiation treatment and tumor response was checked at 2-3 month intervals thereafter. Treatment response and local recurrence were evaluated using follow-up dynamic CT scans and serum tests for alpha-fetoprotein (AFP) and prothrombin, which is induced by vitamin $\mathrm{K}$ absence or antagonist-II (PIVKAII). Tumor response was determined by the criteria established by Kwon et al. [14]. Described briefly, complete response (CR) was defined as the disappearance of any intratumoral arterial enhancement in all target lesions. Partial response (PR) was defined as at least a $30 \%$ decrease in the sum of the diameters of viable target lesions. Progressive disease (PD) was defined as an at least $20 \%$ increase in the sum of the diameters of viable target lesions or the appearance of a new lesion. Stable disease (SD) was defined as a tumor status that did not meet any of the above criteria.

\section{Statistical analysis}

Unpaired $t$ tests were used to compare numerical data and the Yates $2 \times 2$ chi-square test or Fisher exact probability test was used to compare categorical data. Statistical analyses were performed using SAS 6.13 software (SAS Institute Inc., Cary, NC). The sample size of 49 patients was sufficient to detect a change in mean scores of RORTC QLQ-C30.

\section{Results}

Hydrogen water improved the QOL of patients receiving radiotherapy

The QOL of the patients who were given placebo water deteriorated significantly within the first month of radiotherapy (Figure 1A). There were no differences between the groups in the QOL subscales for fatigue, depression, or sleep. Gastrointestinal (GI) symptoms are one of the most common complaints of patients undergoing radiotherapy and are considered to have a high impact on the patient's QOL after 6 weeks of radiotherapy. The patients consuming hydrogen water experienced significantly less appetite loss and fewer tasting disorders compared to the patients consuming placebo water. No significant difference was seen in the mean scores for vomiting or diarrhea (Figure 1B).

\section{Hydrogen water mitigated oxidative stress marker during radiotherapy}

Before treatment, there were no differences in total hydroperoxide levels, representative of total dROM levels, between the treatment groups. Radiotherapy markedly increased total hydroperoxide levels in the patients consuming placebo water. However, drinking hydrogen water prevented this increase in total serum hydroperoxide, as determined by the dROM test (Figure 2A), indicating decreased oxidative stress during radiotherapy in the

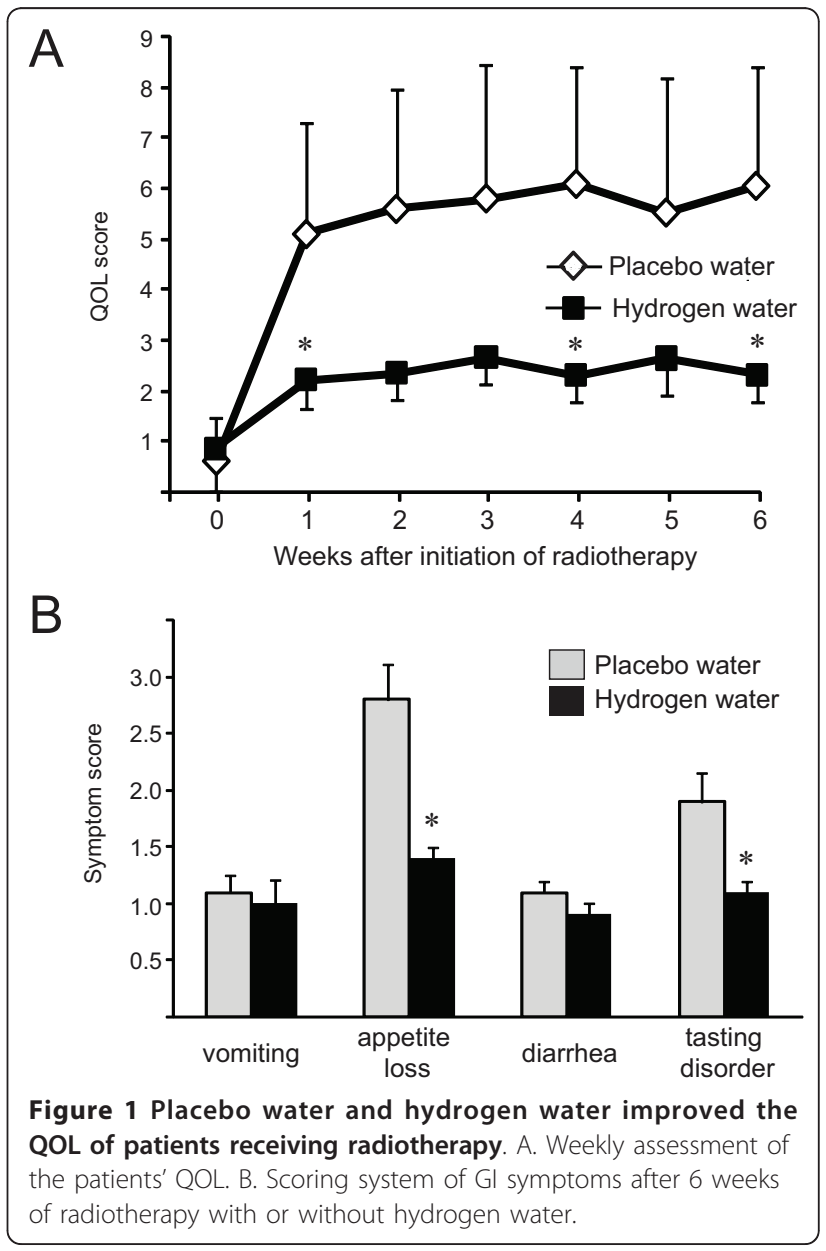




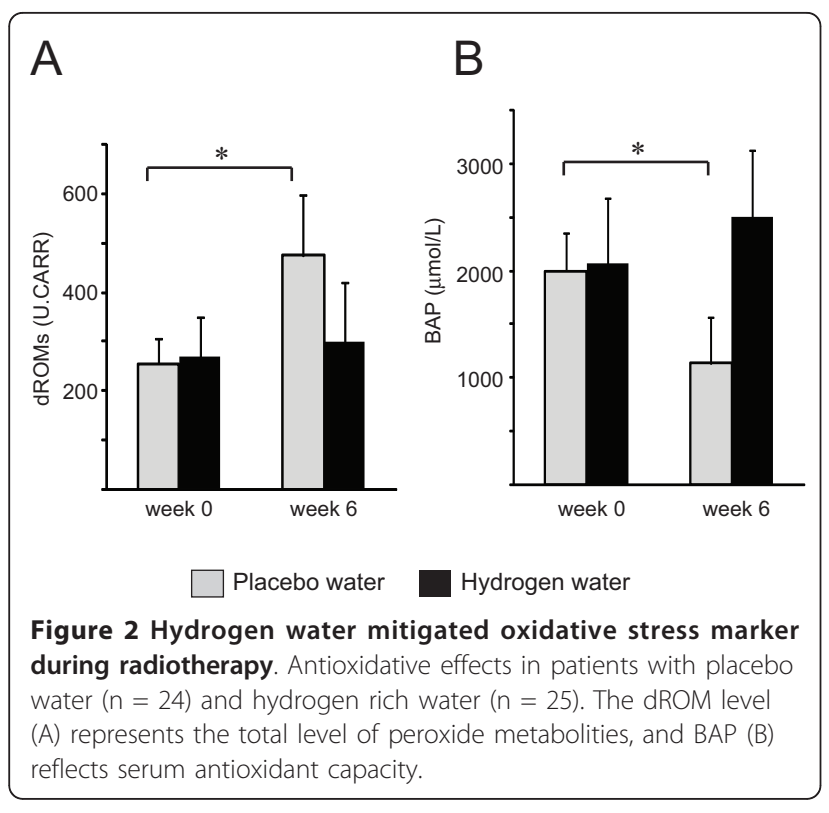

patients who consumed hydrogen water. Similarly, endogenous serum antioxidant activity significantly deteriorated during radiotherapy in the patients consuming placebo water, and biologic antioxidant activity was maintained in patients who consumed hydrogen-rich water, even after 6 weeks of radiotherapy (Figure 2B).

\section{Hydrogen water did not compromise the radiation treatment efficacies}

Tumor response to radiotherapy was similar between the treatment groups, and 12 of $24(50.0 \%)$ patients in the placebo group and 12 of $25(48 \%)$ patients in hydrogen water group exhibited either a completed response (CR) or a partial response (PR). There were no patients in either group with progressive disease (PD) during the follow-up period (3 months). Thus, drinking hydrogen water did not compromise the anti-tumor effects of radiotherapy.

\section{Hydrogen treatment did not alter liver function or blood composition during radiotherapy}

There were no significant differences in aspartate aminotransferase, alanine aminotransferase, gamma-glutamyl transpeptidase $(\gamma$-GTP) and total cholesterol levels at week 0 and week 6 , regardless of the type of water consumed (Table 2), indicating that hydrogen water consumption did not alter liver function. Similarly, there were no significant differences in red blood cell count, white blood cell count, or platelet count between patients consuming hydrogen water and patients consuming placebo water (Table 3).

\section{Discussion}

To our knowledge, this is the first report demonstrating the benefits of drinking hydrogen water in patients receiving radiation therapy for malignant tumors. This finding may provide the foundation for a clinically applicable, effective, and safe strategy for the delivery of hydrogen gas to mitigate radiation-induced cellular injury. Patients experience GI symptoms and decreased QOL during radiotherapy. These symptoms usually occur as a result of the body repairing damage to healthy cells, are particularly common towards the end of a course of radiation treatment, and can last for some time. The symptoms and their impact on QOL can be worsened by having to travel to the hospital each day. Drinking hydrogen-rich water improved the QOL of the patients receiving radiotherapy and did not require additional hospital visits. Although overall survival of patients with malignant tumors should remain oncologists' primary concern, survival should also be interpreted in light of symptom palliation and overall QOL,

Table 2 Changes in liver function tests

\begin{tabular}{|c|c|c|c|c|c|c|}
\hline & \multicolumn{3}{|c|}{ Placebo } & \multicolumn{3}{|c|}{ Hydrogen water } \\
\hline & all $(n=25)$ & male $(n=17)$ & female $(n=8)$ & all $(n=25)$ & male $(n=16)$ & female $(n=9)$ \\
\hline \multicolumn{7}{|l|}{$\overline{\mathrm{AST}(I U / L)}$} \\
\hline Week 0 & $24.8 \pm 9.1$ & $25.6 \pm 5.7$ & $23.1 \pm 10.4$ & $25.3 \pm 6.7$ & $25.9 \pm 5.3$ & $23.9 \pm 8.3$ \\
\hline Week 6 & $26.3 \pm 6.7$ & $26.9 \pm 7.1$ & $25.4 \pm 6.8$ & $26.8 \pm 8.2$ & $27.2 \pm 9.9$ & $26.4 \pm 5.1$ \\
\hline \multicolumn{7}{|l|}{$\overline{\mathrm{ALT}(\mathrm{IU} / \mathrm{L})}$} \\
\hline Week 0 & $27.4 \pm 15$ & $28.1 \pm 11$ & $26.5 \pm 17$ & $26.9 \pm 8.7$ & $27.1 \pm 6.7$ & $26.7 \pm 10.3$ \\
\hline Week 6 & $28.8 \pm 14$ & $28.7 \pm 16$ & $27.6 \pm 12$ & $28.1 \pm 6.5$ & $28.8 \pm 7.3$ & $27.6 \pm 9.9$ \\
\hline \multicolumn{7}{|l|}{$\overline{\gamma-G P T(I U / L)}$} \\
\hline Week 0 & $61.9 \pm 54.3$ & $62.3 \pm 35.6$ & $60.5 \pm 64.7$ & $62.3 \pm 26.2$ & $62.1 \pm 34.8$ & $62.4 \pm 47.9$ \\
\hline Week 6 & $62.8 \pm 22.8$ & $63.2 \pm 16.5$ & $62.7 \pm 25.9$ & $63.6 \pm 36.2$ & $63.9 \pm 54.2$ & $63.2 \pm 27.4$ \\
\hline \multicolumn{7}{|l|}{$\overline{\mathrm{AST}(\mathrm{IU} / \mathrm{L})}$} \\
\hline Week 0 & $24.8 \pm 9.1$ & $25.6 \pm 5.7$ & $23.1 \pm 10.4$ & $25.3 \pm 6.7$ & $25.9 \pm 5.3$ & $23.9 \pm 8.3$ \\
\hline Week 6 & $26.3 \pm 6.7$ & $26.9 \pm 7.1$ & $25.4 \pm 6.8$ & $26.8 \pm 8.2$ & $27.2 \pm 9.9$ & $26.4 \pm 5.1$ \\
\hline
\end{tabular}


Table 3 Peripheral blood cell counts

\begin{tabular}{|c|c|c|c|c|c|c|}
\hline & \multicolumn{3}{|c|}{ Placebo } & \multicolumn{3}{|c|}{ Hydrogen water } \\
\hline & all $(n=25)$ & male $(n=17)$ & female $(n=8)$ & all $(n=25)$ & male $(n=16)$ & female $(n=9)$ \\
\hline \multicolumn{7}{|c|}{ The number of leukocytes $\left(\times 10^{2} / \mu \mathrm{L}\right)$} \\
\hline Week 0 & $55.8 \pm 15.6$ & $58.5 \pm 12.7$ & $52.8 \pm 16.4$ & $56.2 \pm 16.7$ & $57.3 \pm 17.2$ & $55.4 \pm 15.1$ \\
\hline Week 6 & $53.9 \pm 21.4$ & $54.1 \pm 22.7$ & $53.7 \pm 19.8$ & $54.7 \pm 28.7$ & $55.1 \pm 31.2$ & $53.8 \pm 19.4$ \\
\hline \multicolumn{7}{|c|}{ The number of erythrocytes $\left(\times 10^{4} / \mu \mathrm{L}\right)$} \\
\hline Week 0 & $474.2 \pm 38.3$ & $492.3 \pm 45.8$ & $460.8 \pm 30.5$ & $482.5 \pm 42.1$ & $496.6 \pm 50.7$ & $472.9 \pm 36.4$ \\
\hline Week 6 & $462.1 \pm 52.4$ & $473.8 \pm 42.1$ & $456.4 \pm 62.2$ & $479.5 \pm 36.5$ & $486.4 \pm 29.4$ & $470.7 \pm 40.5$ \\
\hline \multicolumn{7}{|c|}{ The number of thrombocytes $\left(\times 10^{4} / \mu \mathrm{L}\right)$} \\
\hline Week 0 & $25.7 \pm 6.5$ & $26.4 \pm 4.7$ & $24.7 \pm 5.9$ & $26.4 \pm 7.1$ & $26.9 \pm 5.5$ & $26.1 \pm 4.8$ \\
\hline Week 6 & $24.5 \pm 4.7$ & $25.9 \pm 2.8$ & $23.4 \pm 6.4$ & $25.7 \pm 4.8$ & $26.1 \pm 4.7$ & $25.3 \pm 3.9$ \\
\hline
\end{tabular}

because the side effects of radiotherapy may negate the putative benefit of improved survival. Oral intake of daily hydrogen-supplemented water might be a prophylactic strategy to improve QOL of the patients receiving radiotherapy.

Although the mechanisms underlying the beneficial effects of hydrogen-rich water during radiotherapy have not been clearly elucidated, drinking hydrogen-supplemented water reduced $\mathrm{dROM}$ levels and maintained BAP levels in the serum, suggesting hydrogen-rich water exhibits potent systemic antioxidant activity. Previous experimental studies have linked daily consumption of hydrogen-rich water with improvement of a number of conditions in rodent models, including reducing atherosclerosis in apolipoprotein E knockout mice [10], alleviating cisplatin-induced nephrotoxicity [15], reducing vitamin $C$ deficiency-induced brain injury [16], preventing chronic allograft nephropathy after renal transplantation [17], and ameliorating cognitive defects in senescence-accelerated mice [9] and a Parkinson's disease model [7]. In human studies, consumption of hydrogen-rich water prevented adult-onset diabetes and insulin resistance [11], as well as oxidative stress in potential metabolic syndrome [8].

Radiotherapy is associated with an increase in ROS, followed by damage to DNA, lipids, and proteins, and activation of transcription factors and signal transduction pathways. It has been estimated that $60-70 \%$ of the ionizing radiation-induced cellular damage is caused by hydroxyl radicals [18]. Therefore, a number of trials with the goal of reducing adverse effects due to excess ROS production have been performed with antioxidants delivered during the course of radiotherapy. Supplementation with $\alpha$-tocopherol improves the salivary flow rate and maintains salivary parameters [19]. Treatment with the antioxidant enzyme superoxide dismutase prevented radiotherapy-induced cystitis and rectitis in bladder cancer patients receiving radiotherapy [20]. In addition, the combined use of pentoxifylline and vitamin E reduced radiation-induced lung fibrosis in patients with lung cancer receiving radiotherapy [21]. Thus, in general, supplementation with antioxidants is likely to offer overall benefits in the treatment of adverse effects of radiotherapy. However, not all antioxidants can afford radioprotection [22-24]. Furthermore, of significant concern is the finding that high doses of antioxidants administered as adjuvant therapy might compromise the efficacy of radiation treatment and increase of the risk of local recurrence of cancer $[25,26]$. Hence, the relatively lower toxicity associated with the use of these antioxidant agents is appealing, but not at the cost of poor tumor control. In contrast, in this study, drinking hydrogen-rich water did not affect radiotherapy's anti-tumor effects. Our results may suggest that hydrogen water functions not only as an antioxidant, but also plays a protective role by inducing radioprotective hormones or enzymes. Although further studies are warranted to elucidate the safety of hydrogen-rich water and determine the optimal concentration of hydrogen in drinking water, as well as involved mechanisms, daily intake of hydrogen-rich water may be a promising approach for counteracting radiation-induced impairments to QOL. This therapeutic use of hydrogen is also supported by the work of Qian et $a l$., who demonstrated that treating human lymphocyte AHH-1 cells with hydrogen before irradiation significantly inhibited ionizing irradiation-induced apoptosis and increased cell viability in vitro. They also showed that injection of hydrogen-rich saline could protect the gastrointestinal endothelia from radiation-induced injury, decrease plasma malondialdehyde and intestinal 8-hydroxydeoxyguanosine levels, and increase plasma endogenous antioxidants in vivo [27].

\section{Conclusions}

In conclusion, our study demonstrated that drinking hydrogen-rich water improved QOL and reduced oxidative markers in patients receiving radiotherapy for liver tumors. This novel approach of oral intake of hydrogenrich water may be applicable to a wide range of radiation-related adverse symptoms. 


\section{List of abbreviations}

ROS: reactive oxygen species; QOL: quality of life

\section{Acknowledgements}

This research was supported by a Daimaru Research Foundation grant awarded to YG.

\section{Author details}

'Department of Therapeutic Radiology, Gyeongsang National University Hospital, Gyeongsang Institute of Health Sciences, Jinju, Korea. ${ }^{2}$ Department of Radiation Oncology, Catholic University Medical College, Seoul, Korea. ${ }^{3}$ Graduate School of Health Science, Suzuka University of Medical Science, Suzuka, Japan. ${ }^{4}$ Department of Cardiothoracic Surgery, University of Pittsburgh, Pittsburgh, Pennsylvania, USA. ${ }^{5}$ Department of Surgery, University of Pittsburgh, Pittsburgh, Pennsylvania, USA.

\section{Authors' contributions}

KMK, YNK and IBC participated in the radiation therapy and the data accumulation. YG participated in the design of the study and performed the statistical analysis. TK and $Y T$ and participated in its design and coordination. AN conceived of the study, and drafted the manuscript. All authors read and approved the final manuscript.

\section{Competing interests}

The authors declare that they have no competing interests.

Received: 23 February 2011 Accepted: 7 June 2011

Published: 7 June 2011

\section{References}

1. Ringborg U, Bergqvist D, Brorsson B, Cavallin-Stahl E, Ceberg J, Einhorn N, Frodin JE, Jarhult J, Lamnevik G, Lindholm C, Littbrand B, Norlund A, Nylen U, Rosen M, Svensson H, Moller TR: The Swedish Council on Technology Assessment in Health Care (SBU) systematic overview of radiotherapy for cancer including a prospective survey of radiotherapy practice in Sweden 2001-summary and conclusions. Acta Oncol 2003, 42(5-6):357-65.

2. Zhao W, Robbins ME: Inflammation and chronic oxidative stress in radiation-induced late normal tissue injury: therapeutic implications. Curr Med Chem 2009, 16(2):130-43.

3. Citrin D, Cotrim AP, Hyodo F, Baum BJ, Krishna MC, Mitchell JB: Radioprotectors and mitigators of radiation-induced normal tissue injury. Oncologist 2010, 15(4):360-71.

4. Ohsawa I, Ishikawa M, Takahashi K, Watanabe M, Nishimaki K, Yamagata K, Katsura K, Katayama Y, Asoh S, Ohta S: Hydrogen acts as a therapeutic antioxidant by selectively reducing cytotoxic oxygen radicals. Nat Med 2007, 13(6):688-94.

5. Buchholz BM, Kaczorowski DJ, Sugimoto R, Yang R, Wang Y, Billiar TR, McCurry KR, Bauer AJ, Nakao A: Hydrogen inhalation ameliorates oxidative stress in transplantation induced intestinal graft injury. Am J Transplant 2008, 8(10):2015-24.

6. Huang C, Kawamura T, Toyoda Y, Nakao A: Recent Advances in Hydrogen Research as a Therapeutic Medical Gas. Free Rad Res 2010, 44(9):971-82.

7. Fujita K, Seike T, Yutsudo N, Ohno M, Yamada H, Yamaguchi H, Sakumi K, Yamakawa Y, Kido MA, Takaki A, Katafuchi T, Tanaka Y, Nakabeppu Y, Noda M: Hydrogen in Drinking Water Reduces Dopaminergic Neuronal Loss in the 1-methyl-4-phenyl-1,2,3,6-tetrahydropyridine Mouse Model of Parkinson's Disease. PLoS One 2009, 4(9):e7247.

8. Nakao A, Toyoda Y, Sharma P, Evans M, Guthrie N: Effectiveness of hydrogen rich water on antioxidant status of subjects with potential metabolic syndrome-an open label pilot study. J Clin Biochem Nutr 2010, 46(2):140-9.

9. Gu Y, Huang CS, Inoue T, Yamashita T, Ishida T, Kang KM, Nakao A: Drinking hydrogen water ameliorated cognitive impairment in senescence-accelerated mice. J Clin Biochem Nutr 2010, 46(3):269-76.

10. Ohsawa I, Nishimaki K, Yamagata K, Ishikawa M, Ohta S: Consumption of hydrogen water prevents atherosclerosis in apolipoprotein $\mathrm{E}$ knockout mice. Biochem Biophys Res Commun 2008, 377(4):1195-8.

11. Kajiyama S, Hasegawa G, Asano M, Hosoda H, Fukui M, Nakamura N, Kitawaki J, Imai S, Nakano K, Ohta M, Adachi T, Obayashi H, Yoshikawa T: Supplementation of hydrogen-rich water improves lipid and glucose metabolism in patients with type 2 diabetes or impaired glucose tolerance. Nutr Res 2008, 28(3):137-43.

12. Aaronson NK, Ahmedzai S, Bergman B, Bullinger M, Cull A, Duez NJ, Filiberti A, Flechtner H, Fleishman SB, de Haes JC, et al: The European Organization for Research and Treatment of Cancer QLQ-C30: a qualityof-life instrument for use in international clinical trials in oncology. J Natl Cancer Inst 1993, 85(5):365-76.

13. Ezaki S, Suzuki K, Kurishima C, Miura M, Weilin W, Hoshi R, Tanitsu S, Tomita Y, Takayama C, Wada M, Kondo T, Tamura M: Resuscitation of preterm infants with reduced oxygen results in less oxidative stress than resuscitation with 100\% oxygen. J Clin Biochem Nutr 2009, 44(1):111-8.

14. Kwon JH, Bae SH, Kim JY, Choi BO, Jang HS, Jang JW, Choi JY, Yoon SK, Chung KW: Long-term effect of stereotactic body radiation therapy for primary hepatocellular carcinoma ineligible for local ablation therapy or surgical resection. Stereotactic radiotherapy for liver cancer. BMC Cancer 2010, 10:475.

15. Nakashima-Kamimura N, Mori T, Ohsawa I, Asoh S, Ohta S: Molecular hydrogen alleviates nephrotoxicity induced by an anti-cancer drug cisplatin without compromising anti-tumor activity in mice. Cancer Chemother Pharmacol 2009, 64(4):753-61.

16. Sato Y, Kajiyama S, Amano A, Kondo Y, Sasaki T, Handa S, Takahashi R, Fukui M, Hasegawa G, Nakamura N, Fujinawa H, Mori T, Ohta M, Obayashi H, Maruyama N, Ishigami A: Hydrogen-rich pure water prevents superoxide formation in brain slices of vitamin C-depleted SMP30/GNL knockout mice. Biochem Biophys Res Commun 2008, 375(3):346-50.

17. Cardinal JS, Zhan J, Wang Y, Sugimoto R, Tsung A, McCurry KR, Billiar TR, Nakao A: Oral Administration Of Hydrogen Water Prevents Chronic Allograft Nephropathy In Rat Renal Transplantation. Kidney Int 2009, 77(2):101-9.

18. Vijayalaxmi, Reiter RJ, Tan DX, Herman TS, Thomas CR Jr: Melatonin as a radioprotective agent: a review. Int I Radiat Oncol Biol Phys 2004, 59(3):639-53.

19. Chitra S, Shyamala Devi CS: Effects of radiation and alpha-tocopherol on saliva flow rate, amylase activity, total protein and electrolyte levels in oral cavity cancer. Indian J Dent Res 2008, 19(3):213-8.

20. Sanchiz F, Milla A, Artola N, Julia JC, Moya LM, Pedro A, Vila A: Prevention of radioinduced cystitis by orgotein: a randomized study. Anticancer Res 1996, 16(4A):2025-8.

21. Misirlioglu CH, Demirkasimoglu T, Kucukplakci B, Sanri E, Altundag K Pentoxifylline and alpha-tocopherol in prevention of radiation-induced lung toxicity in patients with lung cancer. Med Oncol 2007, 24(3):308-11.

22. Xavier S, Yamada K, Samuni AM, Samuni A, DeGraff W, Krishna MC, Mitchell JB: Differential protection by nitroxides and hydroxylamines to radiation-induced and metal ion-catalyzed oxidative damage. Biochim Biophys Acta 2002, 1573(2):109-20.

23. Prasad KN, Cole WC, Kumar B, Che Prasad K: Pros and cons of antioxidant use during radiation therapy. Cancer Treat Rev 2002, 28(2):79-91.

24. Ladas EJ, Jacobson JS, Kennedy DD, Teel K, Fleischauer A, Kelly KM: Antioxidants and cancer therapy: a systematic review. J Clin Oncol 2004, 22(3):517-28.

25. Bairati I, Meyer F, Gelinas M, Fortin A, Nabid A, Brochet F, Mercier JP, Tetu B, Harel F, Abdous B, Vigneault E, Vass S, Del Vecchio P, Roy J: Randomized trial of antioxidant vitamins to prevent acute adverse effects of radiation therapy in head and neck cancer patients. J Clin Oncol 2005, 23(24):5805-13.

26. Meyer F, Bairati I, Fortin A, Gelinas M, Nabid A, Brochet F, Tetu B: Interaction between antioxidant vitamin supplementation and cigarette smoking during radiation therapy in relation to long-term effects on recurrence and mortality: a randomized trial among head and neck cancer patients. Int J Cancer 2008, 122(7):1679-83.

27. Qian L, Cao F, Cui J, Huang Y, Zhou X, Liu S, Cai J: Radioprotective effect of hydrogen in cultured cells and mice. Free Radic Res 2010, 44(3):275-82.

\section{doi:10.1186/2045-9912-1-11}

Cite this article as: Kang et al:: Effects of drinking hydrogen-rich water on the quality of life of patients treated with radiotherapy for liver tumors. Medical Gas Research 2011 1:11. 